cardiomyopathies are rather more superficial. The repeated reference in the former chapter to 'Berger' muscular dystrophy suggests little personal familiarity with genetic disorders.

Taken as a whole this is a book with a lot of valuable information in it, in keeping with the high standard always set by this series.

The publishers may wish to note two points. Firstly, the type setting is associated with a gross excess of hyphenation, which I have noticed in previous books produced by the same publisher. The use of automated typesetting techniques is no excuse for such an irritating fault. Secondly, the price is $£ 52$ which will severely limit the number of people purchasing this book and many libraries will decline to take it in these economically difficult times.

If the publishers really wish the book to sell they should have faith in their editors and contributors and produce it at a lower price for a wider audience. This series is too important to be relegated to obscurity by being priced out of the market.

Peter S Harper

\section{A Colour Atlas of Clinical Genetics}

By Michael Baraitser and Robin M Winter. (Pp 159; figures + tables. $£ 35$.) London: Wolfe Medical Publications. 1983.

This compact volume contains an abundance of excellent illustrations in a well designed format, placing emphasis on clinical photographs rather than descriptive text.

In the first five chapters the basic principles of genetics are described in a simple way for those not primarily involved in clinical genetics. Chapters 6 and 7 cover chromosome disorders and dysmorphic syndromes, while the remaining 12 chapters deal with disorders of particular systems, such as bone dysplasias, eye, skin, neurological, and muscle disorders.

Throughout the book the text highlights key features and the inheritance pattern of each disorder and many classification tables are included. A particularly useful practical guide to risk estimation and counselling in congenital deafness is given in chapter 9.

This book is a most helpful addition to current publications on syndrome identification, bringing together extensive experience of both rare and eommon disorders. It will be of value not only to geneticists and paediatricians, but also to obstetricians, general practitioners, students, and nurses. It is small enough to carry around easily and should be available in all out-patient clinics where these types of disorders are encountered, as well as paediatric and maternity wards, where it will provide a most useful source to aid diagnosis.

Helen M Kingston

\section{Developments in Human Reproduction and their Eugenic and Ethical Implications}

Edited by C O Carter. (Pp 256; figures + tables. $£ 18 \cdot 50, \$ 32 \cdot 00$.) London: Academic Press. 1983.

It is curious that, judging by exposure in the media, developments in human reproduction and the "new genetics' appear to generate more controversy and debate than issues such as global starvation and the prospect of nuclear annihilation, which would seem to be much more pressing. Yet it is a fact that much of society is more preoccupied with the possible problems of tomorrow than with those facing it today, so it is appropriate that these Proceedings of the 19th Annual Symposium of the Eugenics Society should be published in this well produced, relatively inexpensive, and highly readable volume.

The papers presented fall roughly into three groups. The first deals with the physiological and technological aspects of contraception, AID, in vitro fertilisation, and in vitro culture. All of these papers recognise the ethical difficulties and the Galton Lecture by Dr Edwards is particularly thoughtful. The second group relates to clinical genetics in its wider sense as it impinges upon the fetus, society, and the extended family. The concluding papers deal directly with the eugenic, ethical, and tangled legal implications of the new technology and its application.

This book is both instructive and stimulating and should do much to dispel the unfounded anxieties and misconceptions of those who fear that we are on the brink of a Brave New World. It can be readily recommended to all those concerned with the broader implications of medical genetics.

I D Young

\section{Hypermobility of Joints}

By P Beighton, R Grahame, and $\mathrm{H}$ Bird. (Pp xiii + 178; figures + tables. DM 110.) Berlin, Heidelberg, New York: Springer-Verlag. 1983.

This little book of 170 pages ranges widely over the whole field of diseases, disorders, and disasters that may lead to an unusual degree of joint mobility, from Charcot's joints through rheumatoid arthritis, traumatic rupture of ligaments, and various genetic disorders, to simple double jointedness. It is written 
from the standpoint of the physician and rheumatologist rather than the orthopaedic surgeon, and covering, as it does, so many topics and disciplines within a short space only a brief discussion of each can be given.

A short introductory chapter deals with symptoms and possible associated signs such as skin laxity, herniae, and mitral valve prolapse, and also includes methods of measurement. Chapter 2 notes the difficulty of assessment and describes a scoring system, as well as illustrating the routine orthopaedic examination of joints in some detail. Chapters 3 and 4 deal respectively with chemistry and biomechanics, including structure of collagen and elastin. Clinical aspects, management, and some case histories are described in chapters 5,6 , and 7 . Chapter 8 is devoted to 'hypermobility in art and sport' and the final chapter deals with a variety of inherited syndromes in which hypermobility of joints is a feature, with a thumbnail sketch of each.

This well produced little book is predominantly an anecdotal approach to the subject, covering a very wide field in a relatively few pages.

\section{RUTH WYNNE-DAVIES}

\section{Soft Tissue Ossification}

By J M Connor. (Pp xiii +146 ; figures + tables. $£ 27 \cdot 50$, DM 110.) Berlin, New York: Springer Verlag. 1983.

The reason why soft tissues, such as muscle, may sometimes ossify is unknown, and descriptions of ectopic ossification most often occupy obscure corners in large orthopaedic texts. Yet fixation of joints with bars of bone can be disastrous, especially when added to other injuries or when recurrent and progressive.

Dr Connor now brings the subject out into the open in a very readable monograph. It would be reasonable to ask why he has done so; answers are to be found in Dr Victor McKusick's foreword and in the author's own work. The central disorder dealt with in this book, which led to Dr Connor's interest in ectopic ossification, is the excessively rare but disabling disease of fibrodysplasia ossificans progressiva (often still known as myositis ossificans progressiva), which progressively fixes its victims into increasing rigidity from infancy. In this apparently heritable disorder of connective tissue, characteristic skeletal abnormalities combine with ectopic ossification in major muscles to immobilise the spine, chest, and large joints. From the clinical problems posed by this distressing condition $\mathrm{Dr}$ Connor expanded his interest into other causes of ectopic ossification, and this book is the result.
The book is well written, well illustrated, andळ comprehensive. Ossification associated with major $\stackrel{\overrightarrow{\mathrm{D}}}{\rightarrow}$ injury, tumours, fibrodysplasia ossificans progressiva, $\underset{\Rightarrow}{\Rightarrow}$ neurological, and other conditions are dealt with in $\stackrel{5}{?}$ order, and the last two sections are concerned witho experimental ectopic bone formation and the factors thought to regulate osteogenesis. Each $\frac{\bar{c}}{\frac{1}{}}$ chapter can be consulted separately with advantage $e_{\Omega}^{\mathbb{\infty}}$ and interest.

This is a book for the specialist. It comes at an opportune time to remind us of the many causes of ectopic ossification and the clinical problems which $\vec{\omega}$ follow.

At least this book is a source of information not readily obtainable elsewhere; at best it is a direct challenge to those who think they understand cell biology and osteogenesis to find out why bonew forms outside the skeleton and how to prevent it. N

ROGER SMITH

Early Mammalian Development:

Parthenogenetic Studies

Developmental and Cell Biology Series No 14. Byc M H Kaufman. (Pp xi + 276; figures + tablef.+ £32.50.) Cambridge, London: Cambridge U画versity Press. 1983.

Dr Kaufman is an undisputed authority in the fielda of mammalian parthenogenesis and it is appropriate, $\frac{\circ}{8}$ therefore, that he has been given the opportunity in this volume to assemble and evaluate criticallyo the accumulated information available to date. The monograph forms one of a series dealing with developmental and cell biology in which short critical accounts of a particular area are required. The work answers well to that description. It isoclear and well written and should be of great value 3 to the mammalian embryologist and developmentali biologist. The author also expresses the hope that, $\frac{0}{3}$ with the technical developments which have taken place in the field over recent years, parthenogenones and parthenogenetically derived material might also $\frac{\text { o }}{2}$ be used by researchers in genetics, mutagenesis, and $=$ carcinogenesis. The availability of haploid and ${ }^{\circ}$ homozygous diploid cell lines could be of immense value in such studies.

A historical introduction tells us that studies in $\mathrm{E}$ mammalian parthenogenesis date back to the 1930s with major bursts of further advance taking place at approximately 10 year intervals until the presentक time. Enormous gaps, however, remain in the knowledge.

The opening chapter provides the non-specialist reader with valuable terminology (for readers on $\frac{\Phi}{\Phi}$ 